\title{
Bienestar psicosocial en el proceso de cuidados de enfermería de un paciente adolescente con VIH/SIDA
}

\author{
Psychosocial well-being in the nursing care process of an adolescent \\ patient with HIV / AIDS
}

\author{
María Arellán-Regalado ${ }^{1}$ \\ Neumi Martínez-Carbajal ${ }^{1}$
}

\begin{abstract}
Resumen
El síndrome de inmunodeficiencia adquirida se asocia a múltiples infecciones exponiendo a contraer determinadas neoplasias en el estadio avanzado de la enfermedad; perjudicando y alterando no solo aspectos biológicos sino psicosociales de quien lo padece. Con el presente reporte de caso se abordó un paciente adolescente de 19 años portador del VIH/SIDA, quien fue diagnosticado a los 18 años por contagio sexual, se encontraba internado en un Hospital Nacional del Cono Norte por complicaciones en su enfermedad. Ante la referida problemática, se planteó realizar las intervenciones de enfermería, centrándose en la mejora de la calidad de vida del paciente enfocado en el bienestar psicosocial. El plan de cuidados se inició empleando la valoración de los 13 dominios de la Taxonomía NANDA, según aspectos positivos y negativos. Mediante las intervenciones se consiguió mejorar los aspectos negativos priorizados como diagnósticos: baja autoestima situacional, descuido personal, ansiedad y riesgo de soledad, de la misma manera se logró mejorar la calidad de vida del paciente con el fomento de su bienestar psicosocial en este estadio de su enfermedad. Palabras clave: Bienestar; Impacto psicosocial; Adolescente; Atención de enfermería (Fuente: DeCS).
\end{abstract}

\begin{abstract}
Acquired immunodeficiency syndrome is associated with multiple infections, in which it is exposed to contracting neoplasms in the advanced stage of the disease; harming and altering not only biological aspects but psychosocial aspects of the sufferer. This case report presents a 19-year-old adolescent patient with HIV / AIDS, who was diagnosed at 18 years of age by sexual contact, was admitted to a National Hospital of the Northern Cone for complications with the development of her illness. Given the problematic reference, in this case report it was proposed to carry out nursing treatments, focusing on the improvement of the patient's quality of life focused on psychosocial well-being. The care plan was modified using the assessment of the 13 domains of the NANDA Taxonomy, according to positive and negative aspects. Through the difficulties, the prioritized negative aspects will be improved as diagnoses: low situational selfesteem, personal neglect, anxiety and risk of loneliness, in the same way the patient's quality of life will be improved with the promotion of their psychosocial well-being in this stage of his illness.
\end{abstract}

Keys words: Wellness; Psychosocial impact; Teen; Nursing Care (Source: DeCS).

Para citar:

Arellán M, Martínez N. Bienestar psicosocial en el proceso de cuidados de enfermería de un paciente adolescente con VIH/SIDA. CASUS. 2019;4(3):194-203.

DOI: $10.35626 /$ casus.3.2019.86

${ }^{1}$ Hospital Cayetano Heredia.

Correo electrónico: macamar0414@gmail.com
Fecha de recepción: 19-11-18

Fecha de envío a pares: 15-08-19

Fecha de aprobación por pares: 29-11-19

Fecha de aceptación: 04-12-19 


\section{INTRODUCCIÓN}

El virus de inmunodeficiencia humana (VIH) daña al sistema inmunológico mediante la destrucción de los glóbulos blancos, por lo cual se expone a contraer otras enfermedades. Según la Organización Mundial de Salud (OMS) en la actualidad existen 2 millones de adolescentes que están infectados con el VIH/SIDA. Asimismo, la tasa de mortalidad aumentó a un $50 \%$ en esta etapa de vida (1). Según el Ministerio de Salud (MINSA) en el Perú las regiones más afectadas por el contagio de esta enfermedad son Lima y Callao con un $70 \%$ y un $97 \%$ por casos de transmisión sexual (2).

La adolescencia es un periodo en donde inician cambios por la transición de la infancia hacia la vida adulta (3). Por otro lado, si a un paciente adolescente, se le añade una enfermedad crónica (VIH/SIDA) esta etapa pudiera ser aún más dificultosa. Es por ello, que se presentan modificaciones principalmente en el estado socioemocional de su vida como para su familia. Se debe considerar que la no consideración del bienestar psicosocial puede traer consecuencias negativas como la mala convivencia en su enfermedad, una incorrecta adhesión al tratamiento o incluso tomar actitudes perjudiciales que agraven su salud (3).

Se debe promover un cuidado holístico mirando el estado emocional y social de los pacientes portadores de esta enfermedad. Asimismo, se considera que el enfermero (a) es el promotor principal de dichos cuidados (3). El lenguaje y los cuidados de una manera universal en enfermería son esenciales en el cuidado del paciente con VIH/SIDA. Por ende, se reconoce la importancia de la comunicación enfermero-paciente adolescente para realizar una valoración adecuada y poder identificar los diagnósticos de enfermería sobre el aspecto psicosocial del paciente así poder intervenir (4).

Por esta razón, el objetivo fue realizar las intervenciones de enfermería a un adolescente con VIH/SIDA priorizando el estado emocional y social en la convivencia de su enfermedad. Para el estudio se utilizó el modelo de los 13 dominios de la taxonomía II clasificación de los diagnósticos NANDA (North American Nursing Diagnosis Association) (5), el NOC (Nursing Outcomes Classification) (6) para los objetivos y el NIC (Nursing Interventions Classification) (7) para las intervenciones realizadas.

\section{PRESENTACIÓN DEL CASO CLÍNICO}

Se presentó a un paciente adolescente (YRB) de 19 años, sexo masculino, natural de Lima, con bajos recursos económicos, secundaria completa y de religión católico. Asimismo, fue diagnosticado con VIH/SIDA a los 18 años de edad por contagio sexual. El paciente estuvo internado por seis días en un hospital por descompensación al presentar diarreas, deshidratación y náuseas. A pocos meses la madre del paciente refiere que su hijo recae e ingresa por emergencia a un Hospital Nacional del Cono Norte por dolor abdominal, debilidad muscular, decaimiento y dificultad respiratoria. Con signos vitales $\mathrm{T}^{\circ}: 37.5^{\circ} \mathrm{C}, \mathrm{FC}: 101 \mathrm{x}$, FR: 26 x', P/A: 100/65 mmHg, SatO2: $95 \%$ y con un recuento de linfocitos CD4 igual a 105/ ul. Posteriormente quedó internado en observación y mediante una evaluación médica se le diagnosticó PVVS (paciente viviendo con el virus del SIDA) y con TARGA (Tratamiento Antirretroviral de Gran Actividad). Por ende, se observó decaimiento y abandono de sí mismo respecto a la higiene. Además, se mostró afectado su estado emocional, manifestándose poco comunicativo, triste, débil y temeroso. Paciente quedó hospitalizado en el servicio de Medicina tropical.

\section{VALORACIÓN GENERAL}

Se encontró al paciente adolescente hospitalizado en el servicio de medicina tropical y se tuvo el apoyo sistémico de los 13 dominios de la taxonomía de NANDA I para la valoración del caso clínico. Se tomó en cuenta principalmente los aspectos negativos y se priorizaron dominios relacionados al estado emocional y social, ya que refería: "No quiero hacer nada, me siento muy débil, solo quiero dormir"," tengo mucho miedo por lo que está pasando, me quiero ir" (ver tabla $1)$. 
Tabla 1. Análisis de los Dominios, según aspectos positivos y negativos

\begin{tabular}{|c|c|c|}
\hline Dominio & Aspectos positivos & Aspectos negativos \\
\hline 1. Promoción de la salud & No se observa. & $\begin{array}{l}\text { No conoce mucho sobre su } \\
\text { estado de salud. }\end{array}$ \\
\hline 2. Nutrición & $\begin{array}{l}\text { Dieta completa + LAV. } \\
\text { Apetito normal. }\end{array}$ & $\begin{array}{l}\text { Peso: } 48 \mathrm{~kg} . \\
\text { Talla: } 1.66 \mathrm{~cm} \text {. } \\
\text { Índice de masa corporal de } 17.7 \\
\text { (delgadez leve). }\end{array}$ \\
\hline 3. Eliminación e Intercambio & $\begin{array}{l}\text { Ventilación espontánea. } \\
\text { Diuresis espontánea. }\end{array}$ & Abdomen ascítico \\
\hline 4. Actividad / Reposo & Ausencia de tos. & $\begin{array}{l}\text { Grado de dependencia II. } \\
\text { Estado de higiene inadecuado. } \\
\text { Disminución de la fuerza } \\
\text { muscular. } \\
\text { Descuido personal. } \\
\text { Presencia de caries. } \\
\text { Estado de abandono de sí } \\
\text { mismo. }\end{array}$ \\
\hline 5. Percepción / Cognición & $\begin{array}{l}\text { Estado de conciencia: } \\
\text { Escala de coma de Glasgow } \\
15 / 15 \text { puntos } \\
\text { (apertura ocular }=4 \text {; respuesta } \\
\text { verbal }=5 \text {; respuesta motora }=6 \text { ) } \\
\text { Comunicación verbal. }\end{array}$ & Poco comunicativo \\
\hline 6. Autopercepción & Los cinco sentidos normales. & $\begin{array}{l}\text { Estado emocional alterado. } \\
\text { Baja autoestima. }\end{array}$ \\
\hline 7. Rol / Relaciones & $\begin{array}{l}\text { Relación afectiva con su madre. } \\
\text { Su madre es colaboradora. }\end{array}$ & $\begin{array}{l}\text { Su madre se encuentra ansiosa, } \\
\text { preocupada y triste. } \\
\text { Adolescente aislado con un } \\
\text { biombo. }\end{array}$ \\
\hline 8. Sexualidad & No se observa. & No se observa. \\
\hline $\begin{array}{l}\text { 9. Afrontamiento / Tolerancia } \\
\text { al estrés }\end{array}$ & No tuvo intento de suicido. & $\begin{array}{l}\text { Paciente ansioso, preocupado, } \\
\text { triste y temeroso. } \\
\text { Paciente refiere "Tengo miedo } \\
\text { por lo que está pasando y me } \\
\text { quisiera ir del hospital". }\end{array}$ \\
\hline 10. Principio Vitales & Acepta transfusión de sangre. & No solicita ayuda religiosa. \\
\hline 11. Seguridad / Protección & No se observa & $\begin{array}{l}\text { Vías periféricas. } \\
\text { Riesgo de caída por debilidad. }\end{array}$ \\
\hline 12. Confort & $\begin{array}{l}\text { No presenta náuseas. } \\
\text { No tiene fobias. }\end{array}$ & Aislamiento social. \\
\hline 13. Crecimiento / Desarrollo & No se observa. & No se observa. \\
\hline
\end{tabular}

\section{FASE DIAGNÓSTICA}

Al realizar la valoración se plantearon los diagnósticos de enfermería (real y potencial) utilizando la Taxonomía NANDA. Los diagnósticos fueron priorizados con la finalidad de brindar cuidados de enfermería para mejorar su bienestar psicosocial.

\section{Reales:}

- (00119) Baja autoestima situacional r/c deterioro funcional $\mathrm{e} / \mathrm{p}$ conducta no asertiva. Dominio 6, Clase 2.

- (00193) Descuido personal r/c factores estresantes $\mathrm{e} / \mathrm{p}$ higiene personal insuficiente. Dominio 4, Clase 5.

- (00146) Ansiedad r/c estado de salud comprometido e/p dependencia, temor y preocupación. Dominio 9, Clase 2. 


\section{Potencial:}

- (00054) Riesgo de soledad r/c aislamiento social. Dominio 12, Clase 3.

\section{FASE DE PLANIFICACIÓN}

Una vez que se identificaron los aspectos negativos se realizó la priorización de los diagnósticos reales y potenciales de enfermería con la taxonomía II de la NANDA I. Posteriormente, se formularon las intervenciones (NIC) de enfermería para los respectivos objetivos (NOC) (ver tabla 2).

\section{FASE DE EJECUCIÓN}

Se ejecutó el plan de cuidados en 15 días en turnos diarios de 12 horas, a través de las intervenciones y actividades de enfermería según la valoración realizada al paciente con la ayuda de su madre. El objetivo fue acompañarlo en el proceso de la enfermedad durante su hospitalización.

\section{FASE DE EVALUACIÓN}

Mediante la ejecución de las intervenciones planificadas se resolvieron algunos diagnósticos reales entre los cuales intervienen en la recuperación de su salud. Con respecto a la autoestima, el paciente de manera frecuente refería "me siento débil", "no quiero hacer nada", así mismo se encontraba desanimado y contrariado consigo mismo. Por ello, mediante las actividades de enfermería se consiguió potenciar la seguridad, confianza en sí mismo, interés por mejorar conductas inadecuadas. Se favoreció una comunicación abierta y eficaz que le permitió expresar sus miedos y sentimientos, también se le felicitó por su iniciativa de salir a caminar fuera de su habitación. Se logró mejorar la autoestima en donde el paciente mostró interés por su autocuidado con el apoyo de la madre. Se obtuvo una puntuación de Likert de 2 (Raramente positivo) a un Likert 3 (A veces positivo).

Respecto al diagnóstico descuido personal, el adolescente se encontraba desalineado con su imagen e higiene corporal, mostrando estado de abandono de sí mismo. A través de las actividades realizadas se logró mejorar su imagen corporal facilitando que el adolescente se bañase con apoyo de la enfermera por la debilidad que presentaba, se consiguió potenciar su interés por mejorar su aspecto físico y su higiene corporal. El resultado final tuvo una puntuación de Likert 4 (Levemente comprometido) a un Likert 2 (Sustancialmente comprometido).

En la tabla 2, se evidencia el diagnóstico ansiedad en el adolescente debido al estado de salud comprometido por su enfermedad. El adolescente refirió "Tengo miedo por lo que está pasando y me quisiera ir del hospital". Por lo cual se realizaron las planificaciones y actividades de enfermería como la escucha activa frente a los sentimientos estresantes, la previa educación sobre los procedimientos a realizar, se brindó información sobre su salud de manera adecuada al paciente. Al tener la cercanía con el paciente se buscaba la comunicación para mantener siempre un ambiente de confianza y de empatía para identificar sus percepciones y miedos así actuar sobre los mismos. Una vez aplicadas las intervenciones se obtuvo un cambio en los resultados de los indicadores del NOC de un Likert 2 (sustancial) a un Likert 4 (leve).

En cuanto al diagnóstico de riesgo de soledad, se consiguió brindar los cuidados de enfermería como mantener un ambiente de inclusión social con el adolescente. Igualmente, se brindó soporte emocional para el estado de ánimo, se motivó para que exprese sentimientos o realice conversaciones y se buscó de eliminar las barreras de comunicación, como la presencia de un biombo innecesario para el paciente. Asimismo, se solicitó apoyo de la madre para realizar dichas intervenciones. Se obtuvo como resultado final de una puntuación de Likert de 1 (Grave) a un Likert 3 (moderado).

\section{DISCUSIÓN}

Mediante las intervenciones de enfermería realizadas se contribuyó en la mejora del bienestar psicosocial del adolescente. Respecto a la baja autoestima situacional el paciente logró mostrar juicio personal sobre la capacidad de uno mismo durante su estancia hospitalaria, en la cual había 
Tabla 2. Diagnósticos de enfermería: objetivos, intervenciones, actividades y resultados

\begin{tabular}{|c|c|c|c|c|}
\hline $\begin{array}{c}\text { Diagnóstico de enfermería } \\
\text { NANDA }\end{array}$ & $\begin{array}{l}\text { Objetivos planteados } \\
\text { (NOC1) }\end{array}$ & $\begin{array}{l}\text { Intervenciones de } \\
\text { enfermería } \\
\text { (NIC) }\end{array}$ & Actividades & $\begin{array}{l}\text { Resultados de enfermería } \\
\text { (NOC2) }\end{array}$ \\
\hline $\begin{array}{lrr}(00119) & \text { Baja } & \text { autoestima } \\
\text { situacional } & \text { r/c } & \text { deterioro }\end{array}$ & (1205) Autoestima. & $\begin{array}{l}\text { (43509) Manejo de } \\
\text { la conducta. }\end{array}$ & $\begin{array}{l}\text { Establecer límites con el paciente, por ejemplo, si el } \\
\text { paciente presenta conductas inadecuadas como }\end{array}$ & (1205) Autoestima. \\
\hline $\begin{array}{l}\text { funcional e/p conducta no } \\
\text { asertiva. } \\
\text { Dominio: } 6\end{array}$ & $\begin{array}{l}\text { Paciente mostrará el juicio } \\
\text { personal sobre la capacidad } \\
\text { de sí mismo. }\end{array}$ & & $\begin{array}{l}\text { autoevaluarse. } \\
\text { Establecer hábitos, así como a animarle a realizar } \\
\text { actividades sencillas que le demuestren las capacidades }\end{array}$ & $\begin{array}{l}\text { Paciente mostró juicio } \\
\text { personal sobre la capacidad } \\
\text { de uno mismo. }\end{array}$ \\
\hline Autopercepción. & Indicadores: & & que aún conserva. & Indicadores: \\
\hline \multirow[t]{10}{*}{ Clase 2: Autoestima. } & $\begin{array}{l}120501 \text { Verbalizaciones de } \\
\text { auto aceptación. }\end{array}$ & & $\begin{array}{l}\text { Ignorar las conductas inadecuadas. Por el contrario, } \\
\text { conservar una comunicación abierta y eficaz que le }\end{array}$ & $\begin{array}{l}120501 \text { Verbalizaciones de } \\
\text { auto aceptación. }\end{array}$ \\
\hline & $\begin{array}{l}120502 \text { Aceptación de las } \\
\text { propias limitaciones. }\end{array}$ & & permita expresar sus miedos y sentimientos. & $\begin{array}{l}120502 \text { Aceptación de las } \\
\text { propias limitaciones. }\end{array}$ \\
\hline & $\begin{array}{l}120504 \text { Mantenimiento del } \\
\text { contacto ocular. }\end{array}$ & & $\begin{array}{l}\text { Alabar los esfuerzos de autocontrol y utilizar el } \\
\text { contacto físico. Por ejemplo, felicitarle al paciente por } \\
\text { mostrar iniciativa de salir a caminar fuera de su } \\
\text { habitación con una estrechez de mano. }\end{array}$ & $\begin{array}{l}120504 \text { Mantenimiento del } \\
\text { contacto ocular. }\end{array}$ \\
\hline & 120511 Nivel de confianza. & & & 120511 Nivel de confianza. \\
\hline & $\begin{array}{l}120514 \text { Aceptación de } \\
\text { críticas constructivas. }\end{array}$ & & & $\begin{array}{l}120514 \text { Aceptación de } \\
\text { críticas constructivas. }\end{array}$ \\
\hline & $\begin{array}{l}\text { Likert: } 2 \text { (raramente } \\
\text { positivo). }\end{array}$ & & & $\begin{array}{l}\text { Likert: } 3 \text { (a veces positivo). } \\
1 \text { nunca positivo. }\end{array}$ \\
\hline & 1 nunca positivo. & & & 2 raramente positivo. \\
\hline & 2 raramente positivo. & & & 3 a veces positivo. \\
\hline & 3 a veces positivo. & & & 4 frecuentemente positivo. \\
\hline & 4 frecuentemente positivo. & & & 5 siempre positivo. \\
\hline
\end{tabular}


Tabla 2. continua

\begin{tabular}{|c|c|c|c|c|}
\hline $\begin{array}{c}\text { Diagnóstico de enfermería } \\
\text { NANDA }\end{array}$ & $\begin{array}{l}\text { Objetivos planteados } \\
\text { (NOC1) }\end{array}$ & $\begin{array}{l}\text { Intervenciones de } \\
\text { enfermería } \\
\text { (NIC) }\end{array}$ & Actividades & $\begin{array}{c}\text { Resultados de enfermería } \\
\text { (NOC2) }\end{array}$ \\
\hline $\begin{array}{l}\text { (00193) Descuido personal r/c } \\
\text { factores estresantes e/p higiene } \\
\text { personal inadecuada. } \\
\text { Dominio: } 4 \\
\text { Actividad/Reposo. } \\
\text { Clase 5: Autocuidado. }\end{array}$ & $\begin{array}{l}\text { (0305) Autocuidados: higiene. } \\
\text { Paciente mejorará acciones } \\
\text { personales para mantener la } \\
\text { higiene corporal y un aspecto } \\
\text { aseado con apoyo. } \\
\text { Indicadores: } \\
030501 \text { Se lava las manos. } \\
030504 \text { Se limpia los oídos. } \\
030506 \text { Mantiene la higiene oral. } \\
030508 \text { Se lava el cabello. } \\
\text { Likert: } 4 \text { (levemente } \\
\text { comprometido). } \\
1 \text { gravemente comprometido. } \\
2 \text { sustancialmente comprometido. } \\
3 \text { moderadamente comprometido. } \\
4 \text { levemente comprometido. } \\
5 \text { no comprometido. }\end{array}$ & $\begin{array}{l}\text { (1801) Ayuda con el } \\
\text { autocuidado: } \\
\text { Baño/higiene. }\end{array}$ & $\begin{array}{l}\text { Determinar la cantidad y tipo de ayuda } \\
\text { necesitada. Así como mantener rutinas } \\
\text { y establecer horarios para actividades } \\
\text { del autocuidado. } \\
\text { Considerar la cultura del paciente al } \\
\text { fomentar las actividades de } \\
\text { autocuidado. } \\
\text { Facilitar que el paciente se bañe con } \\
\text { apoyo, según corresponda, facilitando } \\
\text { el uso de dispositivos. } \\
\text { Involucrar a la madre para que } \\
\text { participe en baño del paciente. }\end{array}$ & $\begin{array}{l}\text { (0305) Autocuidados: higiene. } \\
\text { Paciente mejoró acciones } \\
\text { personales para mantener la } \\
\text { higiene corporal y un aspecto } \\
\text { aseado. } \\
\text { Indicadores: } \\
030501 \text { Se lava las manos. } \\
030504 \text { Se limpia los oídos. } \\
030506 \text { Mantiene la higiene oral. } \\
030508 \text { Se lava el cabello. } \\
\text { Likert: } 2 \text { (sustancialmente } \\
\text { comprometido). } \\
1 \text { gravemente comprometido. } \\
2 \text { sustancialmente } \\
\text { comprometido. } \\
3 \text { moderadamente } \\
\text { comprometido. } \\
4 \text { levemente comprometido. } \\
5 \text { no comprometido. }\end{array}$ \\
\hline
\end{tabular}


Tabla 2. continua

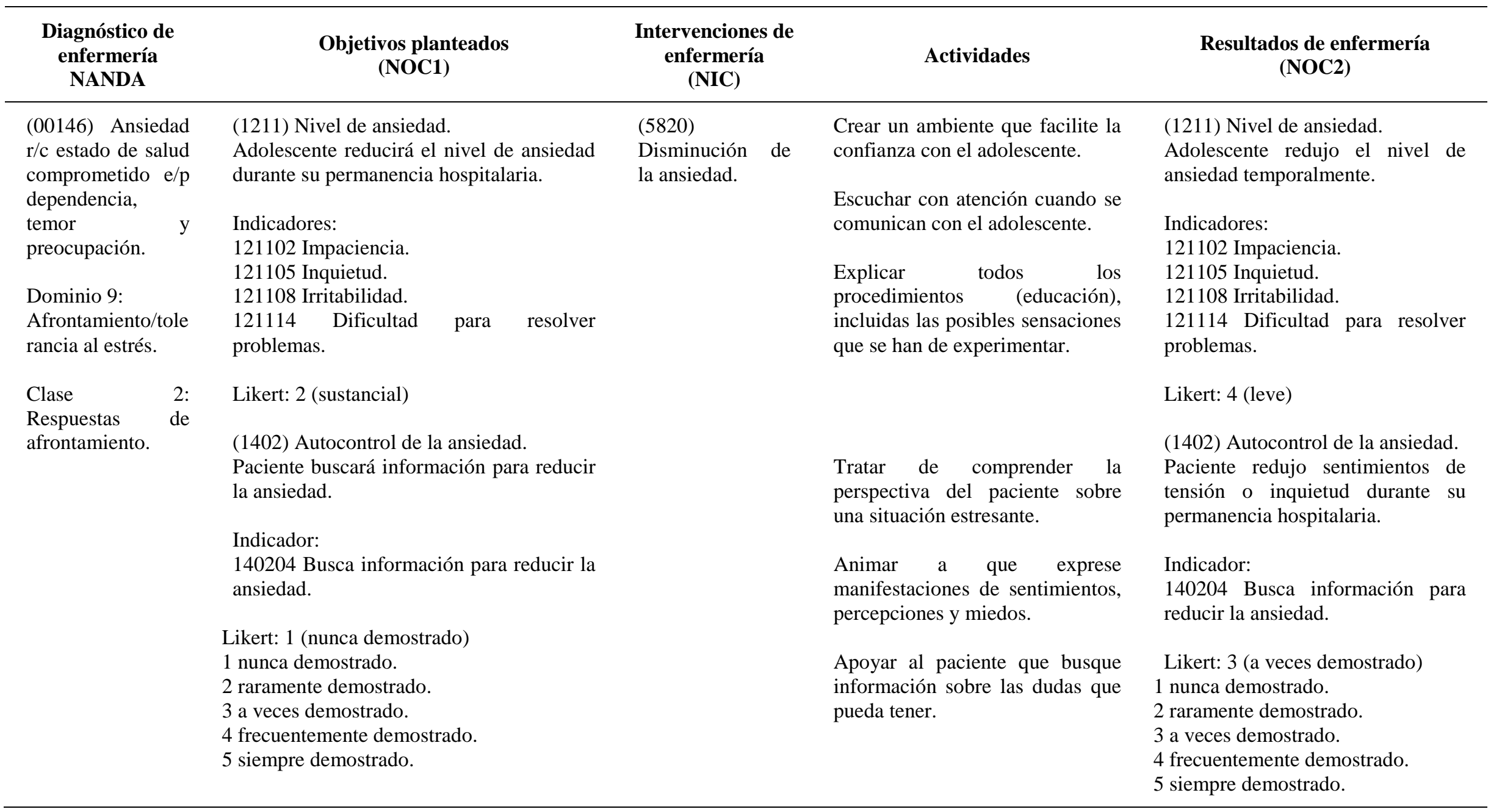


Tabla 2. continua

\begin{tabular}{|c|c|c|c|c|}
\hline $\begin{array}{l}\text { Diagnóstico de } \\
\text { enfermería } \\
\text { NANDA }\end{array}$ & $\begin{array}{l}\text { Objetivos planteados } \\
\text { (NOC1) }\end{array}$ & $\begin{array}{l}\text { Intervenciones de } \\
\text { enfermería } \\
\text { (NIC) }\end{array}$ & Actividades & $\begin{array}{l}\text { Resultados de enfermería } \\
\text { (NOC2) }\end{array}$ \\
\hline \multirow{4}{*}{$\begin{array}{l}(00054) \text { Riesgo de } \\
\text { soledad r/c aislamiento } \\
\text { social y depresión. }\end{array}$} & (1203) Severidad de la soledad. & \multirow{4}{*}{$\begin{array}{l}(6480) \text { Manejo } \\
\text { ambiental. }\end{array}$} & \multirow{3}{*}{$\begin{array}{l}\text { Mantener un ambiente de inclusión del adolescente } \\
\text { con los demás pacientes, por ejemplo, } \\
\text { conversaciones que incluya también al adolescente. }\end{array}$} & (1203) Severidad de la soledad. \\
\hline & Paciente adolescente reducirá & & & Paciente adol \\
\hline & los síntomas emocionales y & & & $\begin{array}{l}\text { Paciente adolescente redujo los } \\
\text { síntomas emocionales y sociales }\end{array}$ \\
\hline & sociales de aislamiento. & & $\begin{array}{l}\text { Motivar a que se relacione con los demás (salir a } \\
\text { pasear por el pasadizo y patio). }\end{array}$ & de aislamiento. \\
\hline $\begin{array}{l}\text { Dominio 12: } \\
\text { Confort }\end{array}$ & Indicadores: & & & Indicadores: \\
\hline \multirow[t]{8}{*}{ Clase 3: Confort social. } & $\begin{array}{l}120307 \text { Sensación de exclusión } \\
\text { social. }\end{array}$ & & $\begin{array}{l}\text { Eliminar barreras que puedan crear exclusión } \\
\text { (biombo). }\end{array}$ & $\begin{array}{l}120307 \text { Sensación de exclusión } \\
\text { social. }\end{array}$ \\
\hline & $\begin{array}{l}120312 \text { Dificultad para } \\
\text { establecer contacto con los } \\
\text { demás. } \\
120315 \text { Fluctuaciones en el } \\
\text { estado de ánimo. }\end{array}$ & $\begin{array}{l}5330 \text { Control del } \\
\text { estado de ánimo }\end{array}$ & $\begin{array}{l}\text { Motivar con expresiones positivas sobre acciones } \\
\text { correctas que realiza. }\end{array}$ & $\begin{array}{l}120312 \text { Dificultad para } \\
\text { establecer contacto con los } \\
\text { demás. } \\
120315 \text { Fluctuaciones en el } \\
\text { estado de ánimo. }\end{array}$ \\
\hline & 120327 Depresión. & & $\begin{array}{l}\text { Animar la madre siga permaneciendo con el } \\
\text { paciente. }\end{array}$ & 120327 Depresión. \\
\hline & Likert: 1 (grave) & 7040 Apoyo al & & Likert: 3 (moderado) \\
\hline & 1 grave. & cuidador principal & Animar a la madre que contribuya con el cuidado y & 1 grave. \\
\hline & 2 sustancial. & & apoyo emocional del paciente. & 2 sustancial. \\
\hline & $\begin{array}{l}3 \text { moderado. } \\
4 \text { leve. }\end{array}$ & & Anımar a la madre qu & $\begin{array}{l}3 \text { moderado. } \\
4 \text { leve. }\end{array}$ \\
\hline & 5 ninguno. & & amigos que visiten al paciente. & 5 ninguno. \\
\hline
\end{tabular}


sido perjudicado por el estado avanzado de su enfermedad. Es importante una conversación abierta y eficaz donde se le permita al adolescente expresar sus miedos y sentimientos, también felicitarlo por su esfuerzo y logros al mostrar interés en salir a caminar fuera de su habitación (8). Asimismo, se comprueba que «El contacto físico puede ser el lenguaje que permite transmitir el mensaje aliviador a quien está en medio de la duda, la soledad y el miedo. El tacto es facilitador de la comunicación» (9). Por ello, son importantes los cuidados porque permiten que el paciente obtenga, refuerce y organice sus propios recursos de afrontamiento frente a la situación y, de esta manera, fortalecer su capacidad de resiliencia y autoestima. En tal sentido, el adolescente logra reconocer que los pensamientos y sentimientos negativos ya no lo ayudan; consciente que se puede auto valorar como persona independiente de la enfermedad, con capacidad de poder afrontar la vida de una forma más positiva (8).

Por otro lado, para el diagnóstico descuido personal el adolescente mejoró en mantener el autocuidado respecto al baño e higiene corporal mediante los cuidados de enfermería. Del mismo modo, fomentar el autocuidado en el adolescente permite promover en él una adopción de conductas saludables desarrollándose a lo largo de su vida, de esta manera mejorar su calidad de vida y disminuir los riesgos a los que está expuesto, como las infecciones oportunistas (10). Asimismo, el informar y crear hábitos de rutina de higiene corporal contribuyen con el mejoramiento del estado del paciente (11).

Frente al diagnóstico de ansiedad que presentaba el adolescente mejoró obteniendo un resultado positivo en situaciones de mayor estrés. Por ello, es importante brindar la información que requiere frente a su enfermedad, ya que la falta de esta puede ser un factor predisponente para alterar la reacción del paciente (12). En un ambiente de confianza esta se logra con una buena comunicación; por ende, se considera que superar las barreras de la comunicación entre el personal de salud y el paciente ayuda a brindar un mejor cuidado para reducir la ansiedad (13). El profesional de enfermería es por lo general el primero en interactuar con el paciente, reconocer y percibir sus sentimientos y posteriormente contribuye a solucionar o aliviar sus problemas (14).

Finalmente, respecto al riesgo de soledad del paciente, las intervenciones de enfermería (NIC) ayudaron a incluirlo socialmente $y$ recibir compañía familiar (madre, y amigos) y a fortalecer su estado emocional. Es por ello, que la interacción social de los pacientes con VIH/SIDA trae consigo una satisfacción en las relaciones personales (13). En tal sentido la enfermera debe mantener un ambiente de inclusión entre los pacientes, por ejemplo, en conversaciones que lo incluyan, eliminar todo tipo de barrera que puedan crear exclusión y así reducir el riesgo de soledad (15). De igual manera, es muy importante el apoyo de los familiares o personas cercanas, ya que así pueden compartir emociones y sentimientos que ayuden a sobrellevar el momento (15).

Entre las dificultades que se encontraron destaca el factor tiempo, ya que no hubo la continuidad deseada en las intervenciones, que ameritan de varios acercamientos o encuentros y así lograr mejorar aspectos de manera integral, debido a la demanda de pacientes y falta de personal de salud. Así mismo, no se contó con el apoyo de los demás familiares (como por ejemplo el padre o hermanos por ser menores de edad). Cabe resaltar que se contó con el apoyo de la madre durante el tiempo de rotación por dicho servicio.

Se recomienda que el personal de enfermería considere optimizar los cuidados de una manera individualizada. Por ende, debe estar preparado para afrontar una situación como el caso presentado, así brindar un cuidado de manera holística con un enfoque al bienestar psicosocial. Por otro lado, la enfermera debe ejecutar cuidados de enfermería oportunos apoyándose en la taxonomía de NANDA, NOC Y NIC que garanticen el bienestar psicosocial del paciente. Finalmente, debido a las necesidades de recursos humanos en dicho servicio, se recomienda a las autoridades que apoyen y contribuyan con el 
aumento del personal de enfermería, de modo que se beneficien los pacientes con los cuidados esenciales de enfermería.

\section{REFERENCIAS BIBLIOGRÁFICAS}

1. Organización Mundial de la Salud (OMS), Lidiar con el VIH en la 6. Moorhead S, Johnson M, Mass adolescencia [Internet]. Ginebra, Suiza: OMS [citado el 14 de julio de 2018]. Disponible en: http://www.who.int/features/2013/ adolescents-hiv/es/

7. Bulecheck GM, Butcher HK, temprano en atención a las personas con VIH [Internet] Perú, Lima: MINSA [citado el 14 de julio de 2018]. Disponible en: http://www.minsa.gob.pe/?op=51 \&nota $=15995$

3. Chütz B, Aline M, Tavares C. La importancia del apoyo socio - 9 . emocional en adolescentes y adultos jóvenes portadores de enfermedad crónica. Enfermería Global. 2013;30(1):388-398.

4. Gómez J, Mayorga M, Pérez J, Rojas L, Orozco L, Camargo F. Prevalencia de diagnósticos de enfermería en personas con VIH/SIDA. Enfermería Global. 2013;32:1-10.

5. Herdman TH, Kamitsuru S NANDA Internacional. Diagnósticos enfermeros: Definiciones y clasificación, 20152017. Barcelona: Elsevier; 2015. Dochterman JM, Wagner CM. Clasificación de intervenciones de Enfermería (NIC). 6ta ed. Barcelona: Elsevier; 2014.

11. Monsalve MA, Medidas de autocuidado que tienen los adolescentes portadores del virus del VIH/SIDA en el hogar San Camilo. (Tesis para Licenciatura). Lima: Universidad Nacional Mayor de San Marcos; 2009.

12. Miguel D, Sánchez F, Tomateo D Síndromes psiquiátricos en personas infectadas con el Virus de la Inmunodeficiencia Humana: una revisión breve. Rev Neuropsiquiatr. 2014;77(2):70-77. en soluciones aplicado al caso de una persona diagnosticada con VIH/SIDA.

Ajayu. 13. Frutos C, Aquino N, Amado D, 2016;14(2):303-333. Ferreira M, Díaz C. Calidad de vida en el paciente con VIH en el servicio de Clínica Médica, Hospital Central - Instituto Previsión Social Paraguay. Artículo original. 2016;11(1):1021.

10. Chávarry MA, Tesen M. Nivel de autocuidado en los adultos jóvenes viviendo con VIH/SIDA atendidos en el programa de tratamiento de antirretroviral de gran actividad del Hospital referencial de Ferreñafe [Tesis para 15. Zambrano G, Tiria M, Rodríguez Licenciatura]. Pimentel: Facultad de Ciencias de la Salud Escuela académico profesional de enfermería; 2017.

14. Achucarro S. Calidad de vida de pacientes con VIH/SIDA y atención integral de enfermería. Artículo original. 2010;5(1):20-34 Y, Gómez J, Vargas A, Pulido S, et al. Práctica de cuidado de los pacientes que conviven con VIH/SIDA desde la perspectiva de sus valores y creencias. Ciencia y cuidado. 2009;6(1):44-50. 